\title{
Synthesis of Fluorocyclotriphosphazene Derivatives and Their Fire-Retardant Finishing on Cotton Fabrics
}

\author{
Li Zhanxiong and Du Liping \\ College of Textile and Clothing Engineering, Soochow University, Suzhou 215021, China \\ Correspondence should be addressed to Li Zhanxiong, lizhanxiong@163.com \\ Received 2 February 2010; Revised 13 June 2010; Accepted 13 June 2010 \\ Academic Editor: Yulin Deng
}

Copyright $\odot 2010$ L. Zhanxiong and D. Liping. This is an open access article distributed under the Creative Commons Attribution License, which permits unrestricted use, distribution, and reproduction in any medium, provided the original work is properly cited.

\begin{abstract}
A series of novel fire-retardant agents, fluorocyclotriphosphazene derivatives with the substitution groups of 2,2,3,3tetrafluoropropoxy groups were synthesized using hexachlorocyclotriphosphazene and 2,2,3,3-tetrafluoropropyl alcohol as starting materials. The synthesized fire-retardant agent was emulsified and applied on the cotton fabric finishing to reduce the flammability and afford water/oil repellency simultaneously. The optimum finishing process was achieved according to the test of cotton finishing with fluorocyclotriphosphazene. The treated cotton showed not only excellent fire-retardant performance, but also water and oil repellency with little change in strength and whiteness.
\end{abstract}

\section{Introduction}

Hexachlorocyclotriphosphazene was widely studied in the late 1970s [1]. Hexachlorocyclotriphosphazene itself exhibits excellent fire-retardant properties due to the high content of phosphorus and nitrogen. But unfortunately, this compound was hydrolytically unstable. Major effort, therefore, have been exerted to prepare phosphorous-nitrogen polymers, such as rubber and elastic material with high-temperatureresistant and low-temperature-resistant properties in military, aerospace industries, and so on. In addition, the hexachlorocyclotriphosphazene has been used as the raw material in syntheses of fire-retardant agents for plastics and fibers, biomedical materials, drug delivery agents, and so on [2-4]. As the hydrolytic stable fire-retardant agents, a wide range of phosphazene derivatives were prepared and reported with the substituent of hydroxyl, amino, carbon carbonyl groups, and other functional groups [5-9].

It is true that the insertion of fluorine-containing substituent into phosphazene macromolecules may lead to an enhancement of the thermal stability, flame resistance, and especially, low-surface energy to the target molecule [10].
There are several ways in which fluorine atoms can be inserted into polyphosphazenes, all of which leading to different polymers showing a wide range of characteristics [11]. In this report, a series of fluorocyclotriphosphazene compounds were synthesized via substitution reaction using hexachlorocyclotriphosphazene and 2,2,3,3-tetrafluoropropyl alcohol as materials. As fluorine-containing phosphorus fire-retardant agent, the fluorocyclotriphosphazene products have been applied on cotton fabrics finishing to reduce the flammability and to afford water/oil repellency simultaneously.

\section{Experimental}

2.1. Materials. Hexachlorocyclotriphosphazene (99.7\% purity) was supplied by Shang Hai Fine Chemical Co. Ltd., China. 2,2,3,3-tetrafluoropropyl alcohol, and emulsifier agent Span-60 were supplied by Shang Hai Jia Chen Chemical Co. Ltd. The other chemicals and solvents were purchased as reagent-grade materials. Dimethylol dihydroxyethylene urea (DMDHEU) was obtained at 45\% active ingredient as technical grade chemicals from Yingkou Tanyun Chemical Research Institute Corporation. 
2.2. Synthesis of the Fire-Retardant Agent. Fluorocyclotriphosphazene derivatives substituted with 2,2,3,3-tetrafluoropropoxy groups were synthesized according to the reaction as Scheme 1. In the synthesis procedure, the molar ratio of hexachlorocyclotriphosphazene/sodium tetrafluoropropylate was designed to be $1: 3,1: 4$ or $1: 5$. As a result, three fire-retardant agents with the different substitution degree were obtained and coded as $\mathbf{1 a}, \mathbf{1} \mathbf{b}$, and $\mathbf{1}$, respectively.

2.2.1. Trichlorotris(2,2,3,3-tetrafluoropropoxy)cycloph-ophazene(1a). To $100 \mathrm{~mL}$ of tetrahydrofuran (THF) and $158 \mathrm{~g}$ $(1.2 \mathrm{~mol})$ of 2,2,3,3-tetrafluoropropyl alcohol in a $500 \mathrm{ml}$ round-bottomed three-necked flask equipped with stirrer, $27.6 \mathrm{~g}$ of sodium $(1.2 \mathrm{~mol})$ was added stepwise. Sodium tetrafluoropropylate solution was obtained while the metallic sodium disappeared completely.

$96.6 \mathrm{~g}(0.4 \mathrm{~mol})$ of hexachlorocyclotriphosphazene and $350 \mathrm{ml}$ THF were poured into a $1000 \mathrm{ml}$ round-bottom three-necked flask equipped with magnetic stirrer, thermometer, pressure equalizing dropping funnel, and a condenser. After the mixture was heated to $30^{\circ} \mathrm{C}$ under nitrogen, the preprepared sodium tetrafluoropropylate/THF solution was added dropwise within $1 \mathrm{~h}$. The reaction was continued at $50^{\circ} \mathrm{C}$ for another $1 \mathrm{~h}$. The resultant reaction mixture was cooled and filtered; the filtrate was concentrated in vacuum to remove THF and distilled to give $149 \mathrm{~g}$ of product as a clear liquid with the yield of $70.7 \%$ (GC purity is $95.7 \%$ ).

FT-IR $\left(\mathrm{KBr}, \mathrm{cm}^{-1}\right): v 1244.4(\mathrm{P}=\mathrm{N}), 1111.6(\mathrm{C}-\mathrm{O}), 1071.1$ $(\mathrm{P}-\mathrm{O})$ and $547.7(\mathrm{P}-\mathrm{Cl}) .{ }^{1} \mathrm{H}$ NMR: $\delta 5.47 \sim 6.02\left(3 \mathrm{H}, \mathrm{HCF}_{2}-\right)$, $4.20 \sim 4.34\left(6 \mathrm{H},-\mathrm{CH}_{2}-\right)$ ppm. ${ }^{19} \mathrm{~F}$ NMR: $\delta-126.3 \sim 126.4(2 \mathrm{~F})$, $-141.1(2 \mathrm{~F}) \mathrm{ppm}$. Calc. for $\mathrm{C}_{9} \mathrm{H}_{9} \mathrm{~N}_{3} \mathrm{O}_{3} \mathrm{~F}_{12} \mathrm{Cl}_{3} \mathrm{P}_{3}(\%)$ : C, 17.02; H, 1.42; N, 6.62. Found: C, 17.60; H, 1.72; N, 6.10.

2.2.2. Dichlorotetra(2,2,3,3-tetrafluoropropoxy)cycloph-opha$z e n e(\mathbf{l b})$. $\mathbf{1 b}$ was synthesized according to the procedure similar to that described in 1a. Sodium tetrafluoropropylate was prepared by treating of $32.2 \mathrm{~g}(1.4 \mathrm{~mol})$ of sodium and $185 \mathrm{~g}$ (1.4 mol) of 2,2,3,3-tetrafluoropropyl alcohol in $100 \mathrm{~mL}$ THF.

The Sodium tetrafluoropropylate solution was added to $84.5 \mathrm{~g}(0.35 \mathrm{~mol})$ of hexachlorocyclotriphosphazene in $300 \mathrm{ml}$ THF. Stirring was continued for $1 \mathrm{~h}$. By the similar procedure $131 \mathrm{~g}$ of $\mathbf{1 b}$ was obtained with the yield to be $60.3 \%$, and the purity $96.1 \%$.

FT-IR $\left(\mathrm{KBr}, \mathrm{cm}^{-1}\right): v 1230.2(\mathrm{P}=\mathrm{N}), 1111.1(\mathrm{C}-\mathrm{O}), 1069.6$ $(\mathrm{P}-\mathrm{O})$ and $546.9(\mathrm{P}-\mathrm{Cl}) .{ }^{1} \mathrm{H}$ NMR: $\delta 5.73 \sim 6.02\left(4 \mathrm{H}, \mathrm{HCF}_{2}-\right)$, $4.20 \sim 4.53\left(8 \mathrm{H},-\mathrm{CH}_{2}-\right)$ ppm. ${ }^{19} \mathrm{~F}$ NMR: $\delta-126.6 \sim 126.9(2 \mathrm{~F})$, $-140.9(2 \mathrm{~F}) \mathrm{ppm}$. Elemental analysis Calc. for $\mathrm{C}_{12} \mathrm{H}_{12} \mathrm{~N}_{3} \mathrm{O}_{4}$ $\mathrm{F}_{16} \mathrm{Cl}_{2} \mathrm{P}_{3}(\%)$ : C, 19.73; H, 1.64; N, 5.75. Found: C, 20.20; H, $1.72 ; \mathrm{N}, 5.80$.

2.2.3. Chloropenta(2,2,3,3-tetrafluoropropoxy)cycloph-opha$z e n e(1 \mathrm{c})$. 1c was synthesized according to the procedure similar to that described in 1a, Sodium tetrafluoropropylate was prepared by treating of $34.5 \mathrm{~g}(1.5 \mathrm{~mol})$ and $198 \mathrm{~g}$ (1.5 mol) 2,2,3,3-tetrafluoropropyl alcohol in $150 \mathrm{~mL}$ THF.
The preprepared Sodium tetrafluoropropylate solution was added to $72.5 \mathrm{~g}(0.3 \mathrm{~mol})$ hexachlorocyclotriphosphazene and $280 \mathrm{ml}$ THF. Stirring was continued for $1 \mathrm{~h}$. By the similar procedure $140 \mathrm{~g}$ of $1 \mathrm{c}$ was obtained with the yield to be $65 \%$, and the purity $94.7 \%$.

FT-IR $\left(\mathrm{KBr}, \quad \mathrm{cm}^{-1}\right): \quad v 1235.9 \quad(\mathrm{P}=\mathrm{N}), \quad 1111.2(\mathrm{C}-\mathrm{O})$, 1070.1 (P-O) and 548.1(P-Cl). ${ }^{1} \mathrm{H}$ NMR: $\delta$ 5.74 6.02 $\left(5 \mathrm{H}, \mathrm{HCF}_{2}-\right), 4.20 \sim 4.53\left(10 \mathrm{H},-\mathrm{CH}_{2}-\right)$ ppm. ${ }^{19} \mathrm{~F}$ NMR: $\delta$-126.4 126.9 $(2 \mathrm{~F}),-140.9(2 \mathrm{~F}) \mathrm{ppm}$. Elemental analysis Calc. for $\mathrm{C}_{15} \mathrm{H}_{15} \mathrm{~N}_{3} \mathrm{O}_{5} \mathrm{~F}_{20} \mathrm{ClP}_{3}(\%)$ : C, $21.80 ; \mathrm{H}, 1.82 ; \mathrm{N}, 5.09$. Found: C, 22.20; H, 1.69; N, 4.80 .

2.3. Fire-Retardant Finishing Process for Cotton Fabrics. The fabric was firstly immersed in a finishing solution containing fire-retardant agent $45 \%$ (owf), emulsifier agent 25\% (owf), crosslinker agent 5\% (owf), catalyst $\mathrm{MgCl}_{2} 2 \%$ (owf) and urea 5\% (owf), then passed through a laboratory padder with two dips and two nips, dried at $100^{\circ} \mathrm{C}$ for $3 \mathrm{~min}$, and finally cured in a Mathis curing oven at $160^{\circ} \mathrm{C}$ for $3 \mathrm{~min}$. All the ratios presented of emulsifier agent, crosslinkers agent, catalystand urea are based on the weight of fire-retardant agent. The wet pickup of the cotton fabric was approximately $(100 \pm 3) \%$.

2.4. Characterization. The treated and untreated cotton fabrics were observed on FT-TR spectrometer (Nicolet FTIR 5700-Spectrometer, Thermo Fisher Scientific, America) on a $\mathrm{KBr}$ Pellet. ${ }^{1} \mathrm{H}$ NMR spectra were obtained on a Unity Inova-400 spectrometer (Varian, Inc.) using $\mathrm{CDCl}_{3}$ $\mathrm{d}_{1}$ as the solvent. ${ }^{19} \mathrm{~F}$ NMR spectra were recorded on Brucker AM $300(282 \mathrm{MHz})$ spectrometer using trifluoroacetic acid as external standard, downfield shifts being designed as negative.

Thermogravimetric (TGA) and Differential Thermal Analysis (DTA) experiments were carried out using a Diamond TG/DTA 5700 thermogravimetric analyzer (Perkin EImer company, America). All liquid samples for TGA and DTA were measured from $40^{\circ} \mathrm{C}$ to $350^{\circ} \mathrm{C}$ at the heating rate of $10^{\circ} \mathrm{C} / \mathrm{min}$ in a continuous nitrogen gas flow. All cotton samples for TGA and DTA were measured from $50^{\circ} \mathrm{C}$ to $650^{\circ} \mathrm{C}$ at the heating rate of $10^{\circ} \mathrm{C} / \mathrm{min}$ in a continuous nitrogen gas flow.

The surface of fabrics was observed on the scanning electron microscope (S-570, Hitachi). Magnification was 3000x. Wide angle X-ray diffraction measurement were carried out with X-ray multicrystal diffraction(X Pert-Pro MPD, Panalytical, Netherlands), using $\mathrm{CuK}_{\alpha}(\lambda=0.1542 \mathrm{~nm})$ radiation at a scan rate of $2^{\circ} / \mathrm{min}$.

The fire-retardant effect of cotton fabrics was measured according to GB/T 5455-1997 (Textiles-Burning BehaviourVertical method), which is adopted from ISO 6940-2004 (Textile fabrics-Burning behaviour-Determination of ease of ignition of vertically oriented specimens) equivalently. The levels of water repellency of the cotton fabrics were measured in accordance with the AATCC 22 (1996) spray test method. It measures the resistance of fabrics to wetting by pressurized water. The AATCC 22 spray test uses a set small quantity of water placed about four inches over a fabric. The fabric is 


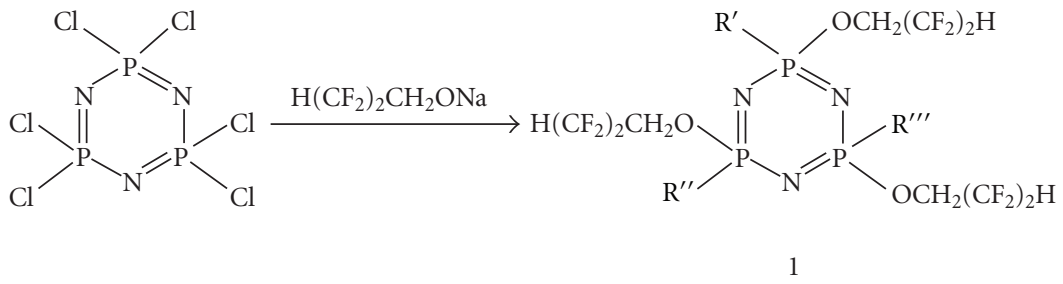

1a: $\mathrm{R}^{\prime}=\mathrm{R}^{\prime \prime}=\mathrm{R}^{\prime \prime \prime}=\mathrm{Cl}$
1b: $\mathrm{R}^{\prime}=\mathrm{R}^{\prime \prime}=\mathrm{Cl} ; \mathrm{R}^{\prime \prime \prime}=\mathrm{OCH}_{2}\left(\mathrm{CF}_{2}\right)_{2} \mathrm{H}$
1c: $\mathrm{R}^{\prime}=\mathrm{Cl} ; \mathrm{R}^{\prime \prime}=\mathrm{R}^{\prime \prime \prime}=\mathrm{OCH}_{2}\left(\mathrm{CF}_{2}\right)_{2} \mathrm{H}$

SCHeme 1

TABLE 1: Evalution standard of the oil repellency.

\begin{tabular}{lcccccccccc}
\hline Scores & 150 & 140 & 130 & 120 & 110 & 100 & 90 & 80 & 70 & 50 \\
\hline Liquid paraffin (\%) & 0 & 10 & 20 & 30 & 40 & 50 & 60 & 70 & 80 & 100 \\
Heptanes (\%) & 100 & 90 & 80 & 70 & 60 & 50 & 40 & 30 & 20 & 0 \\
\hline
\end{tabular}

set at a $45^{\circ}$ angle to the stream of the liquid. The liquid is then allowed to gravity feed through a standardized spreader nozzle. The duration of exposure is about $30 \mathrm{~s}$. At a glancing angle of $45^{\circ}$ to the fabric, a visual rating of how well the water beads up, based on a scale of 100 points, is given to the fabrics. 100 is the best and 70 is considered the lowest passing grade. Oil repellency of cotton fabric was measured according to AATCC 118-2002 test method as below. The fabric was placed on the smooth plane. The corresponding oil with different surface energy was selected to drop on the fabric from low scores to high scores. It passed when the fabric was wetted by oil after 3 minutes until the highest scores were reached. Then the highest scores were the result of oil repellency of the fabric (Table 1). The whiteness of cotton fabric was observed by a whiteness meter (WD-5 whiteness meter, Beijing Optical Instrument Plant).

\section{Results and Discussion}

3.1. Effect of the Fire-Retardant Agent on the Finishing. Fluorocyclotriphosphazene derivatives with different numbers of fluoropropoxy groups substitution were obtained through changing the molar ratio of hexachlorocyclotriphosphazene/sodium tetrafluoropropylate. The obtained three fire-retardant agents of $\mathbf{1 a}, \mathbf{1} \mathbf{b}$, and $\mathbf{1} \mathbf{c}$ were all applied on the cotton fire-retardant finishing.

When 35\% (owf) of the fire-retardant agent was used in the fabric finishing, the treated cotton fabric was subjected to 3 times of home laundering cycles according to AATCC Test Method 124-2005. The burning char length of the cotton treated with different fire-retardant agent before and after washing is summarized in Table 2.

The cotton sample finished with $1 \mathrm{~b}$ was better than the fabric finished with $1 \mathrm{a}$ and $1 \mathrm{c}$ in retaining some fireretardant property after 3 washes. Therefore, only the fireretardant agent of $\mathbf{1 b}$, which was synthesized by controling the ratio of hexachlorocyclotriphosphazene/sodium
Table 2: Durability of the finishing with different fire-retardant agent.

\begin{tabular}{lcc}
\hline $\begin{array}{l}\text { Fire-retardant } \\
\text { agent }\end{array}$ & $\begin{array}{c}\text { Burning char length } \\
\text { Before Washed/cm }\end{array}$ & $\begin{array}{c}\text { Burning char length } \\
\text { After Washed/cm }\end{array}$ \\
\hline 1a & 9.1 & $\begin{array}{c}\text { burnt full length, little char } \\
\text { observed }\end{array}$ \\
1b & 8.9 & 12.1 \\
1c & 8.8 & burnt full length, no char \\
& & observed \\
\hline
\end{tabular}

tetrafluoropropylate of $1: 4$, was adopted in the application research. The Effect of concentration, amount of catalyst agent, crosslinking agent and curing temperature of was studied using $\mathbf{l b}$ as fire-retardant agent.

Table 3 shows the effect of the fire-retardant agent concentration on the performance of the treated cotton fabrics. It can be seen that the increasing fire-retardant agent concentration reduced the burning char length and the breaking strength (weft) as well as the whiteness of the cotton fabric. Taking the fire-retardant performance, the breaking strength and the whiteness into consideration, the optimum concentration of the fire-retardant agent was selected to be $35 \%$ (owf) [9].

3.2. Effect of Catalyst Agent. Catalysts can promote the reaction among the fire-retardant agent, crosslinking agent and cellulose macromolecules during the finishing procedure, and thus improve the fire-retardant performance of the treated fabrics (Table 4). The effect of concentration of the catalyst was similar to that of the fire-retardant agent. It can be seen that the burning char length decreased to $8.4 \mathrm{~cm}$ as the catalyst concentration increased to $3 \%$ (owf). Accordingly, taking the burning char length, the breaking strength and the whiteness into consideration, the optimum catalyst concentration was selected to be $2 \%$ (owf).

3.3. Effect of Crosslinking Agent. Crosslinking agent played a complicated role in the fire-retardant finishing. When cotton fabric is treated with a reactant resin DMDHEU in presence of $\mathrm{MgCl} 2 \cdot 6 \mathrm{H} 2 \mathrm{O}$, the following major reactions are expected to occur. It is the crosslinking reaction between 
TABLE 3

\begin{tabular}{lccccc}
\hline $\begin{array}{l}\text { Fire-retardant agent } \\
\text { concentration/\% }\end{array}$ & Afterflame time/s & Afterglow time/s & $\begin{array}{c}\text { Burning char } \\
\text { length/cm }\end{array}$ & $\begin{array}{c}\text { Breaking strength/N } \\
\text { (weft) }\end{array}$ & Whiteness/\% \\
\hline 20 & 7 & 0 & 13.9 & 225.6 & 83.37 \\
25 & 6 & 0 & 12.5 & 220.7 & 82.85 \\
30 & 4 & 0 & 10.4 & 212.4 & 82.34 \\
35 & 3 & 0 & 8.9 & 206.5 & 81.98 \\
40 & 2 & 0 & 7.8 & 199.5 & 81.35 \\
\hline
\end{tabular}

TABLE 4: Effect of the catalyst agent concentration on the fire-retardant performance.

\begin{tabular}{lccccc}
\hline Catalyst agent $/ \%$ & Afterflame time/s & Afterglow time/s & $\begin{array}{c}\text { Burning char } \\
\text { length/cm }\end{array}$ & $\begin{array}{c}\text { Breaking strength/N } \\
\text { (weft) }\end{array}$ & Whiteness (\%) \\
\hline 0.5 & 3 & 0 & 9.4 & 209.8 & 82.07 \\
1 & 3 & 0 & 9.3 & 209.4 & 82.03 \\
2 & 3 & 0 & 8.9 & 206.5 & 81.98 \\
3 & 2 & 0 & 8.4 & 199.8 & 81.95 \\
\hline
\end{tabular}

Cotton fabric was treated with different catalyst agent concentration, $35 \%$ (owf) fire-retardant agent, $5 \%$ (owf) crosslinking agent, $5 \%$ (owf) urea and was cured at $160^{\circ} \mathrm{C}$ for $3 \mathrm{~min}$.

cellulose molecules and fire retardant agents with the resin molecule afford a bridge between cellulose molecules and fire retardant agents [12]. The major reaction is expected to occur as follow (see Scheme 2).

The crosslinking reaction with cellulose macromolecules and fire-retardant agent via a reactant crosslinking resins can increase the durability or retention of the fire-retardant agents on cotton fibers, and improve the fire-retardant performance of fabrics. As summarized in Table 5, the crosslinking agent improved the fire-retardant performance of the cotton fabrics but made the breaking strength decreased from $211.7 \mathrm{~N}$ to $194.9 \mathrm{~N}$ when increasing the concentration of crosslinking agent from $3 \%$ to $9 \%$. As a result, $5 \%$ concentration was chosen to be the optimum condition of the crosslinking agent.

3.4. Effect of the Curing Temperature. The purpose of curing is to promote the reaction among the fire-retardant agent, cellulose macromolecules and crosslinking agent, and thus to form a stable crosslinked bond among these three components. These crosslinking polymeric networks on the fabric were expected to enhance the fire-retardant performance. The effect of the curing temperature on the fire-retardant performance was investigated and the result was summarized in Table 6. It can be seen that the increase of the curing temperature can improve the fire-retardant performance, which might be attributed to the generation of more crosslinked networks in the case of higher curing temperature. However, the higher curing temperature decreased the whiteness due to the unexpected oxidation reaction, which led to the yellowing of cotton fabric. Taking all factors into consideration, the optimum curing temperature is preferred to be $160^{\circ} \mathrm{C}$.

As a result, the optimum finishing processes was as following: $35 \%$ (owf) of fire-retardant agent $\mathbf{1 b}(35 \% \mathrm{w} / \mathrm{w}$ based on the total bath), 25 owf $\%$ of emulsifier agent, $5 \%$ (owf) of crosslinking agent, $2 \%$ (owf) of catalyst $\left(\mathrm{MgCl}_{2}\right)$, $5 \%$ (owf) of urea, curing temperature of $160^{\circ} \mathrm{C}$ and 3 minutes of curing time. Test was finished to contrast the untreated cotton fabric (A) and the cotton fabric treated with fire-retardant agent $\mathbf{1 b}$ (fabric B) according to the optimum finishing processes.

3.5. FT-IR Spectra Analyses. Figure 1 illustrated the FTIR spectra of the untreated cotton fabric (A) and the cotton fabric treated with fire-retardant agent $\mathbf{1 b}$ (fabric B). In the spectra of the cotton A, The $-\mathrm{OH}, \mathrm{C}-\mathrm{H}$, $\mathrm{CH}_{2}$ and $\mathrm{C}-\mathrm{O}-\mathrm{C}$ absorption bands of cellulose were found at $3411.5 \mathrm{~cm}^{-1}, 2900 \mathrm{~cm}^{-1}, 1431.5 \mathrm{~cm}^{-1}$ and $1060.2 \mathrm{~cm}^{-1}$, respectively. Besides these characteristic absorption bands of cellulose fiber, the FT-IR spectra of the treated cotton B showed three new absorption peaks at $1585.5 \mathrm{~cm}^{-1}$, $1507.1 \mathrm{~cm}^{-1}$, and $814.1 \mathrm{~cm}^{-1}$, which were assigned to $\mathrm{C}=\mathrm{N}$, $\mathrm{N}-\mathrm{H}$ and $\mathrm{P}=\mathrm{N}$ group respectively. It is worthy of noting that the $\mathrm{P}-\mathrm{O}$ absorption band in the treated cotton was shifted to $1031.7 \mathrm{~cm}^{-1}$ as compared with it in cyclotriphosphazene derivative at $1069.6 \mathrm{~cm}^{-1}$, which can be attributed to the introduction of the cellulose groups. FTIR spectra demonstrates that the fire-retardant agent reacted with $-\mathrm{OH}$ groups of cellulose during finishing.

Figure 2 shows the FT-IR spectra of fire-retardant agent $1 \mathbf{b}$. The $\mathrm{P}=\mathrm{N}, \mathrm{C}-\mathrm{O}, \mathrm{P}-\mathrm{O}$ absorption of the fireretardant agent were observed at $1230.2 \mathrm{~cm}^{-1}, 1111.1 \mathrm{~cm}^{-1}$, and $1069.6 \mathrm{~cm}^{-1}$, respectively. It is indicated that $2,2,3,3-$ tetrafluoropropyl alcohol had reacted with hexachlorocyclotriphosphazene. However, the absorption peak at $546.9 \mathrm{~cm}^{-1}$ of $\mathrm{P}-\mathrm{Cl}$ bond suggested that the product of $\mathbf{1 b}$ was fluorocyclotriphosphazene derivative with tetrafluoropropoxy groups substitution partly. 
Cellulose + resin + fire-retardant agents $\longrightarrow$ Cellulose-resin-fire retardant agents

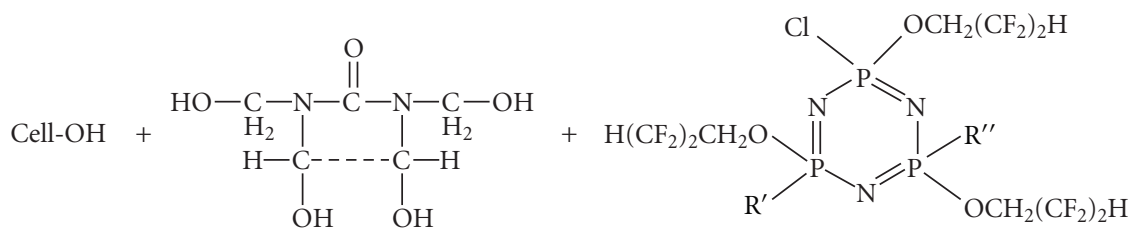

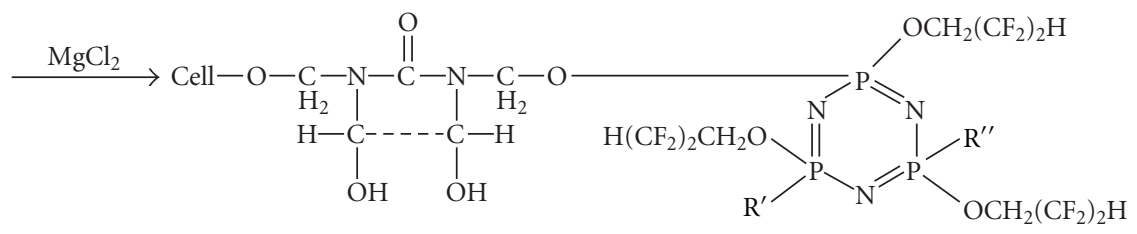

Scheme 2

TABLE 5: Effect of the crosslinking agent concentration on the fire-retardant performance.

\begin{tabular}{lcccc}
\hline $\begin{array}{l}\text { Crosslinking agent } \\
\text { concentration /\% }\end{array}$ & Afterflame time/s & Afterglow time /s & Burning char length/cm & $\begin{array}{c}\text { Breaking strength/N } \\
\text { (weft) }\end{array}$ \\
\hline 3 & 4 & 0 & 9.9 & 211.7 \\
5 & 3 & 0 & 8.9 & 206.5 \\
7 & 2 & 0 & 7.8 & 199.7 \\
9 & 1 & 0 & 6.9 & 194.9 \\
\hline
\end{tabular}

Cotton fabric was treated with crosslink agent, $35 \%$ (owf) fire-retardant agent, $2 \%$ (owf) catalyst $\mathrm{MgCl}_{2}, 5 \%$ (owf) urea and was cured at $160^{\circ} \mathrm{C}$ for 3 min.

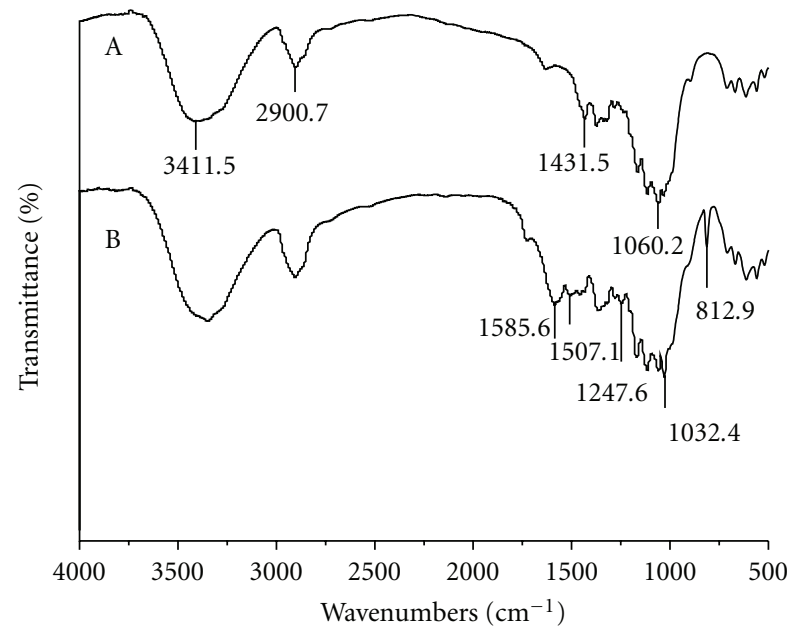

FIGURE 1: FT-IR spectra of the untreated (A) and the treated cotton (B).

3.6. Thermal Analysis. Figure 3 depicted the TG and DTG curves of the fire-retardant agent. The maximum rate of weight loss was determined to be $205^{\circ} \mathrm{C}$ by the peak of the DTG curve in Figure 3.

The fire-retardant finishing of cellulose fiber was mainly carried out by lowering the decomposition temperature and increasing quantity of the solid residual. As it can be seen in the TG curves of the untreated (A) and treated (B) cotton fabrics (Figure 4), the maximum rate of weight loss of the

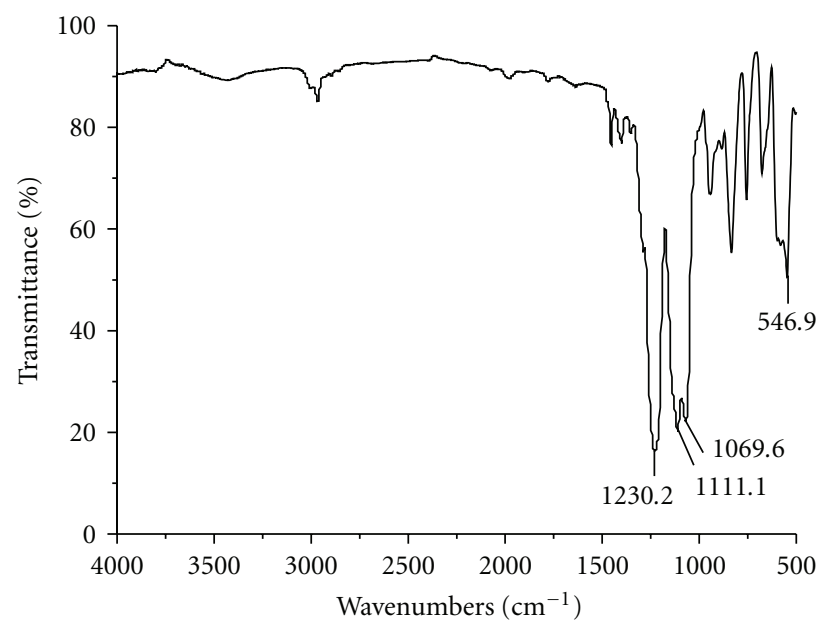

Figure 2: FT-IR spectra of fire-retardant agent $\mathbf{1 b}$.

untreated cotton fabrics appeared at $371^{\circ} \mathrm{C}$ as determined by the peak of DTG process. The weight loss of the untreated cotton was attributed to the thermal decomposition of cellulose, which resulted in the breakage of the main chain of cellulose macromolecule. This result was also confirmed by the endothermic peak at $371^{\circ} \mathrm{C}$ in the DTA curves of the cotton fabric (Figure 5).

In contrast with that of the untreated cotton, the maximum rate of weight loss of the treated cotton fabric was 
TABLE 6: Effect of the curing temperature on the fire-retardant performance

\begin{tabular}{lcccc}
\hline Curing temperature $/{ }^{\circ} \mathrm{C}$ & Afterflame time/s & Afterglow time $/ \mathrm{s}$ & Burning char length/cm & Whiteness $/ \%$ \\
\hline 140 & 5 & 0 & 10.9 & 9.7 \\
150 & 4 & 0 & 8.9 & 81.59 \\
160 & 3 & 0 & 8.4 & 81.98 \\
170 & 2 & 0 & 72.47 \\
\hline
\end{tabular}

Cotton fabric was treated with $45 \%$ (owf) fire-retardant agent, $2 \%$ (owf) catalyst $\mathrm{MgCl}_{2}, 5 \%$ (owf) crosslink agent, $5 \%$ (owf) urea and was cured at different temperature for $3 \mathrm{~min}$.

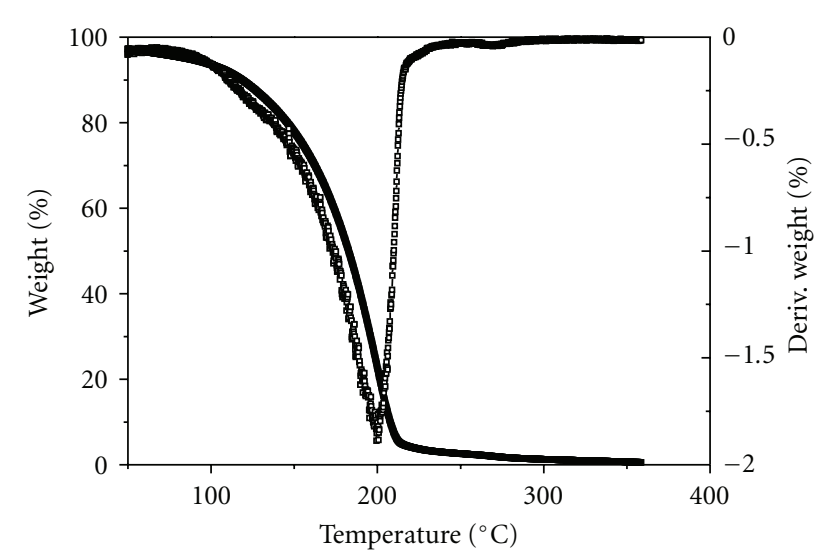

$$
\rightarrow \text { TG }
$$$$
\rightarrow \text { DTG }
$$

FIgURE 3: TG and DTG curves of fire-retardant agent $\mathbf{1} \mathbf{b}$.

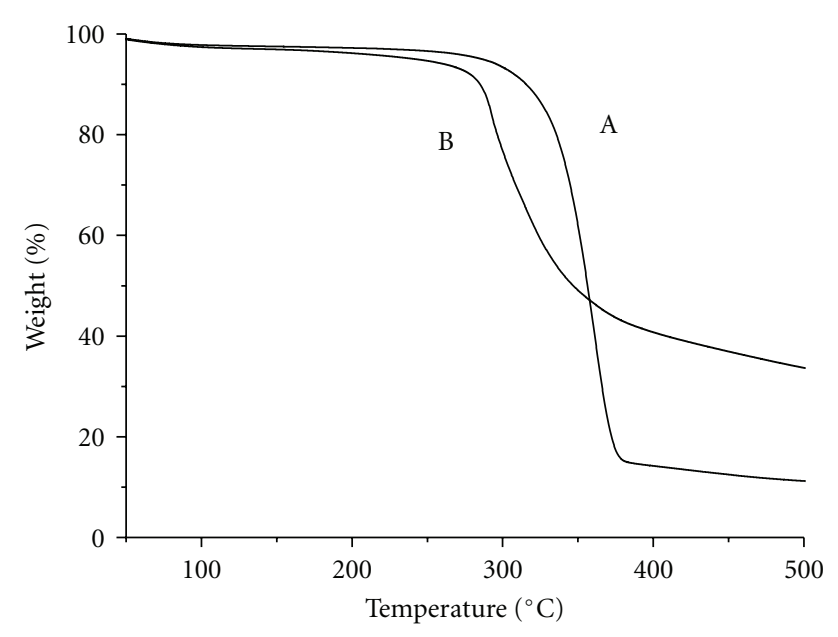

Figure 4: TG curves of the untreated (A) and treated cotton (B).

found to shift to low temperature $\left(290^{\circ} \mathrm{C}\right.$ as determined by both DTG process and DTA curves). It suggests that the fireretardant agent decomposed and escaped from the fabrics before the fire point temperature. On the other hand, as compared with $89 \%$ weight lost of the untreated cotton, the treated fabric was observed with only $66 \%$ weight lost as the temperature increased to $500^{\circ} \mathrm{C}$ (Figure 4). It indicates that the presence of the fire-retardant agent lowered the

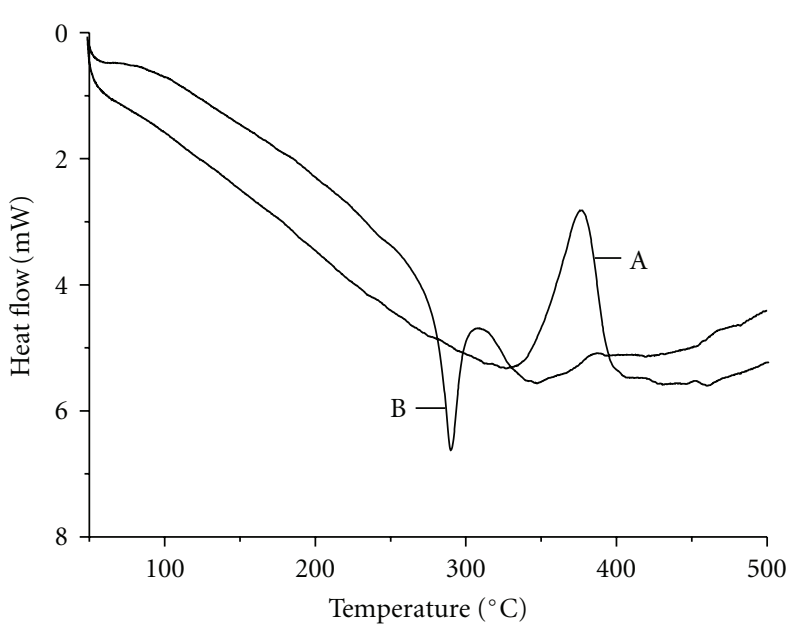

FIgURE 5: DTA curves of the untreated (A) and treated cotton (B).

decomposition temperature and promoted the formation of char in pyrolysis of the fabric.

In general, the reactions of the cellulose dehydration, esterification, charring and phosphorylation were promoted due to the formation of phosphoric acid and phosphate when heating the cotton fabric which has been treated with phosphorus fire-retardant agent. These reactions would contribute to form crosslinking polymeric network in the decomposition, and thus increase the solid residual. The latter can slow the thermal decomposition of the cotton matrix, and the water from cellulose dehydration could absorb large amount of latent heat and lower the temperature.

3.7. Test of Treated Cotton Fabrics. Figure 6 presented the SEM micrographs of the cotton fabrics. The fibers in the treated cotton were found to be covered by a layer of film and be adhered mutually. It suggested that the treated fabric has been covered with a polymeric network, which was formed by the crosslinking reaction among the fire-retardant agent, crosslinking agent and cellulose.

Figure 7 shows the result of X-ray diffraction of the cotton fabrics. Both of the untreated(A) and treated fabric (B) were found to present three strong absorption bands at $2 \theta$ of $22.7^{\circ}, 14.9^{\circ}$ and $16.4^{\circ}$, respectively, and there is little difference between the X-ray diffraction profile of the cottons before and after treatment. It suggested that the fireretardant finishing mainly carried out in amorphous area of the fiber. 


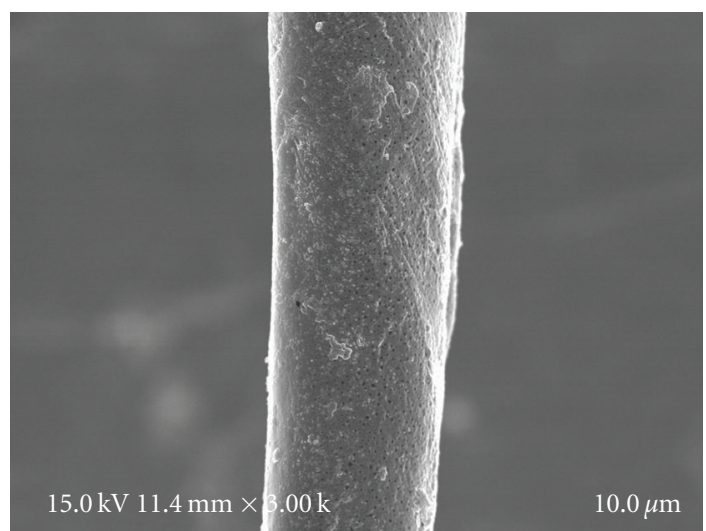

(a)

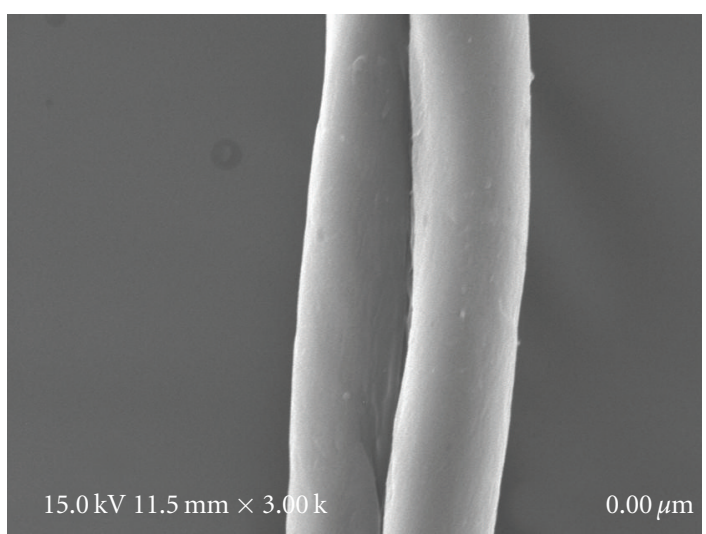

(b)

FIGURE 6: SEM micrographs of the untreated (a) and treated cotton (b).

The water and oil repellency of untreated and treated fabrics were tested. The results showed that the finished cotton fabric could reach level 1 for water repellency and 70 scores for oil repellency. As a result, the introduction of fluorine containing alkyl groups into fire-retardant agent can afford certain water and oil repellency efficiency to fabric finishing.

\section{Conclusions}

In the current research, a kind of fluorocyclotriphosphazene derivative was synthesized and applied to the fire-retardant finishing on cotton fabrics. Good finishing result was achieved by optimizing the finishing process, with the optimum process conditions of: $35 \%$ (owf) of the fire-retardant agent, 5\% (owf) of the crosslinking agent, 2\% (owf) of catalyst $\mathrm{MgCl}_{2}, 160^{\circ} \mathrm{C}$ of curing temperature and curing time of $3 \mathrm{~min}$. The optimum finishing provided the treated cotton fabric with excellent fire-retardant performance. The burning char length of treated cotton was tested to be only $8.9 \mathrm{~cm}$ and whiteness to be $81.9 \%$.

The new fire-retardant agent can reduce the flammability of the treated cotton fabrics with little change in strength and whiteness. Simultaneously, the fluoroalkyl groups in the

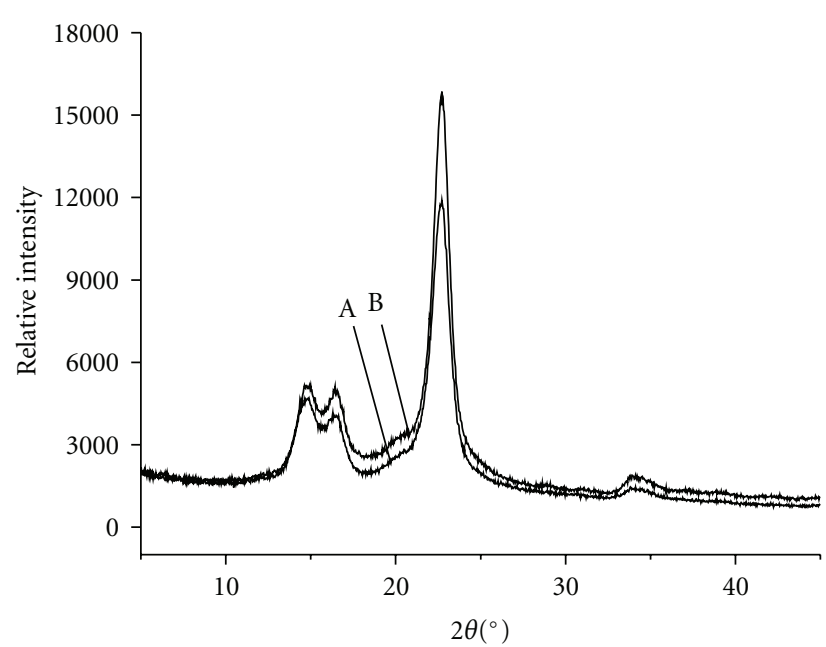

Figure 7: X-ray diffraction profiles of the untreated (A) and treated cotton (B).

phosphorus fire-retardant agent can afford the treated cotton with water and oil repellency.

The $\mathrm{P}-\mathrm{Cl}$ bond in the fire-retardant agent molecule can be used as reactive group to react with $-\mathrm{OH}$ on the cotton fiber. The cotton sample finished with Dichlorotetra(2,2,3,3tetrafluoropropoxy)cyclophophazene $(\mathbf{1 b})$ can retain some fire-retardant property after 3 washes.

\section{Acknowledgment}

The financial support by “Qing Lan” Engineering Funds of Jiangsu Province is greatly appreciated.

\section{References}

[1] P. E. Cassidy, Thermal Stable Polymers: Syntheses and Properties, vol. 306, Marcel Dekker, New York, NY, USA, 1980.

[2] R.-F. Hou and S.-X. Li, "Polyphosphazenes P-N fire-retardant agent," Shanxi Chemical Engineering, vol. 4, pp. 30-31, 1998.

[3] P. Zhu and S.-Y. Sui, "Thermal analysis of fire-retardant cotton fabric and original cotton fabric," Journal of Qingdao University, vol. 15, no. 4, pp. 1-5, 2000.

[4] K. Baljinder, A. Kandola, R. Horrocks, et al., "Complex char formation in flame-retarded fibre-intumescent combinations. Part V. Exploring different fibre/intumescent combinations," Fire and Materials, vol. 25, no. 4, pp. 153-160, 2001.

[5] H. R. Allcock, K. B. Visscher, and Y.-B. Kim, "New polyphosphazenes with unsaturated side groups: use as reaction intermediates, cross-linkable polymers, and components of interpenetrating polymer networks," Macromolecules, vol. 29, no. 8, pp. 2721-2728, 1996.

[6] H. R. Allcock, M. F. Welker, and M. Parvez, "Oxidation of poly[bis(4-methylphenoxy)phosphazene] surfaces and chemistry of the surface carboxylic acid groups," Chemistry of Materials, vol. 4, no. 4, pp. 769-775, 1992.

[7] D. Kumar, G. M. Fohlen, and J. A. Parker, "High-strength fire- and heat-resistant imide resins containing cyclotriphosphazene and hexafluoroisopropylidene groups," Journal of Polymer Science: Polymer Chemistry, vol. 22, no. 4, pp. 927$943,1984$. 
[8] D. Kumar and A. D. Gupta, "Aromatic polyimides based on a novel diamine containing bis-sprio substituted cyclotriphosphazene. american chemical society," Polymer Preprints, vol. 36, no. 1, pp. 247-248, 1995.

[9] L. Y. Qiu and K. J. Zhu, "Novel biodegradable polyphosphazenes containing glycine ethyl ester and benzyl ester of amino acethydroxamic acid as cosu-bstituents: syntheses, characterization, and degradation properties," Journal of Applied Polymer Science, vol. 77, no. 13, pp. 2987-2995, 2000.

[10] J.-Q. Huang, W.-D. Meng, and F.-L. Qing, "Synthesis and repellent properties of vinylidene fluoride-containing polyacrylates," Journal of Fluorine Chemistry, vol. 128, no. 12, pp. 1469-1477, 2007.

[11] M. Gleria, R. Bertani, R. D. Jaeger, and S. Lora, "Fluorine containing phosphazene polymers," Journal of Fluorine Chemistry, vol. 125, no. 2, pp. 329-337, 2004.

[12] K. H. M. Mostafa and M. S. Morsy, "Utilization of newly tailored modified starch products in easy-care finishing," Carbohydrate Polymers, vol. 55, no. 3, pp. 323-331, 2004. 

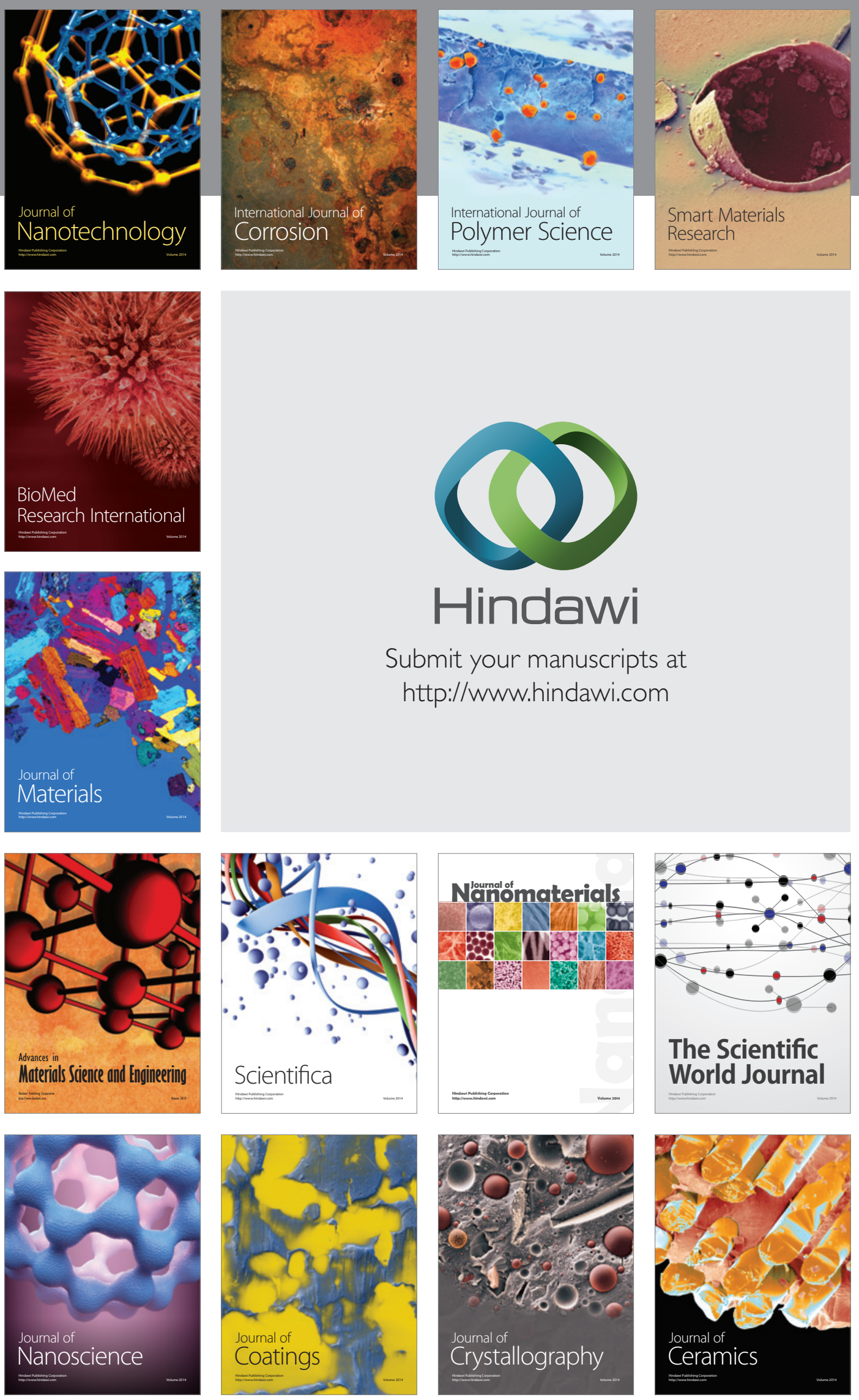

The Scientific World Journal

Submit your manuscripts at

http://www.hindawi.com

\section{World Journal}

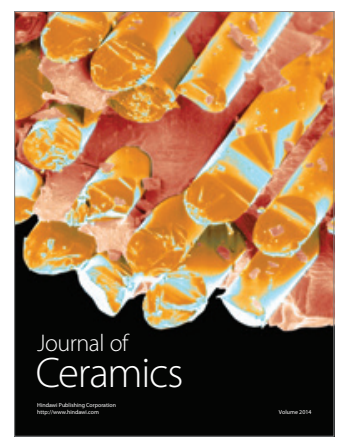

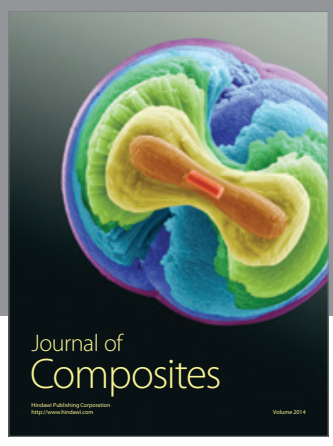
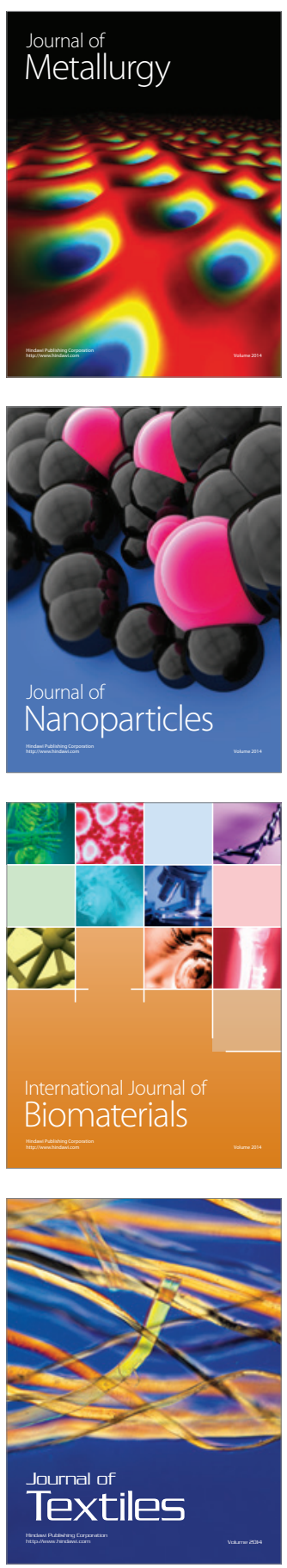